\title{
Ergonomics and design for sustainability in healthcare: ambient assisted living and the social-environmental impact of patients lifestyle
}

\author{
Giuseppe Andreoni ${ }^{\mathrm{a}}$; Pelin Arslan ${ }^{\mathrm{b}}$; Fiammetta Costa ${ }^{\mathrm{b}}$; Sabrina Muschiato ${ }^{\mathrm{b}}$;Maximiliano Romero ${ }^{\mathrm{c}, *}$ \\ ${ }^{a}$ LyPhe: Laboratory for Physical Ergonomics, INDACO Department, Politecnico di Milano, via Durando 38/A, \\ 20158, Milan, Italy. \\ ${ }^{\mathrm{b}}$ HCD: Health Care Design, INDACO Department, Politecnico di Milano, via ghislanzoni 24, 23900 Lecco, Italy. \\ ${ }^{\mathrm{c}}$ PhyCo: Physical Computing Lab , INDACO Department, Politecnico di Milano, via Durando 38/A, 20158, \\ Milan, Italy.
}

\begin{abstract}
This work presents considerations on Ergonomics and Design for Sustainability in the healthcare field based on research experiences of the Technology and Design for Healthcare (TeDH) research group of INDACO (Industrial design, communication, arts and fashion) department of Politecnico di Milano. In order to develop a multidisciplinary approach to design able to answer to specific user needs such as elderly in an environmental sustainable way (1) this paper shows the results we achieved concerning ergonomics and environmental impact in product development (2), the extension of this approach to interior and home design and the advantage of the application of Information Communication Technologies (ICT). ICT can help people with special needs to make their everyday life easier and more safe, at the same time, ICT can make socialenvironmental impact of everyday behavior evident and can be applied to manage sustainability. The specific theme is thus to integrate ergonomics and sustainability competences in the development of Ambient Assisted Living through a ProductService System approach. The concept of product service system has the potential to improve product performances and services, establish new relations and networks with different actors in order to satisfy user needs and apply a systems approach considering environmental, social and economic factors in the users' environment.
\end{abstract}

Keywords: Ergonomics, Ambient Assisted Living, Healthcare, Sustainability

\section{Introduction and objectives}

European population is growing, in 2025 the over$65 \mathrm{~s}$ is predicted to reach more than $30 \%$, which is equivalent to 211 million citizens. By 2050, this group could reach more than $42 \%$, corresponding to almost 265 million people (3). One Italian of 5 is over- 65 and the forecast for 2030 is 1 of 4 (4). In this condition it is easy to prevent a collapse of the National Sanitary System, and in consequence each country tries to find alternatives. In Italy the public healthcare system is autonomously managed by each region, and the policy can be largely different in many of them.

In any case, frequently, traditional hospital infrastructures are not economically sustainable and depend Regional governments' contributions. Lombardia Region is trying to implement strategies focused on dehospitalization and telemonitoring in order to reduce costs (5). Thus many applied research projects focused on home care services based on Information Communication Technology systems has been carried out. The application of Ambient Intelligence for health care purposes has been defined as Ambient

Corresponding author. E-mail: maximiliano.romero@polimi.it. 
Assisted Living.

At this point, and in particular for elderly target population, other problems start to become important like acceptability issues. ICT based projects for telemonitoring or e-health more often do not pay sufficient attention to improvements in human-technology interaction and acceptability. Frequently, many technological well developed products are not implemented because final users don't accept them. European Community is trying to solve this gap with the so called "challenge 5" (Frame Program 7) funding research projects focused on home care for elderly, chronic diseases and disabled people: "This challenge addresses advanced ICT research for sustainable high-quality healthcare, demographic ageing, social and economic inclusion, and the governance of our societies"(6). Accessibility and acceptability issues of technological systems for healthcare is a keypoint for success. More often service provider do not apply ergonomic approaches for service design and development.(7).

Ambient Assisted Living (AAL) results as a privileged context to analyze relationships between Ergonomics and Design for Sustainability since Ambient Intelligence can also be applied as a tool to reach environmental sustainability issues.

Design and ergonomics can offer a key to the development of projects in which the house becomes an interactive environment for non-invasive support to users with special needs related to health but also with "social needs".

The "Media House Project" (figure 1) is an example international research about Ambient Intelligence in domestic contexts developed by Institute for advanced architecture of Catalonia (Iaac) and RD5 Media Archietcture.

Media House is a project of 2001 (figure 1) and its evolution is represented by FabLab House (2011) a solar house based on the extended definition of technological efficiency (figure 2).

These projects show that the interest on issues related to Ambient Intelligence have a real application in the field of sustainability. The concept of "acceptance" of the technology in the living environment has evolved towards a sustainable home idea.

Technologies applied to the management of the built environment can offer opportunities for development of sustainable products and services to improve the quality of life of people with health and social needs, to put forward proposals for the development of a new interaction between the physical world and the digital world, in order to lay the foundations for a new "sustainable way of dwelling".

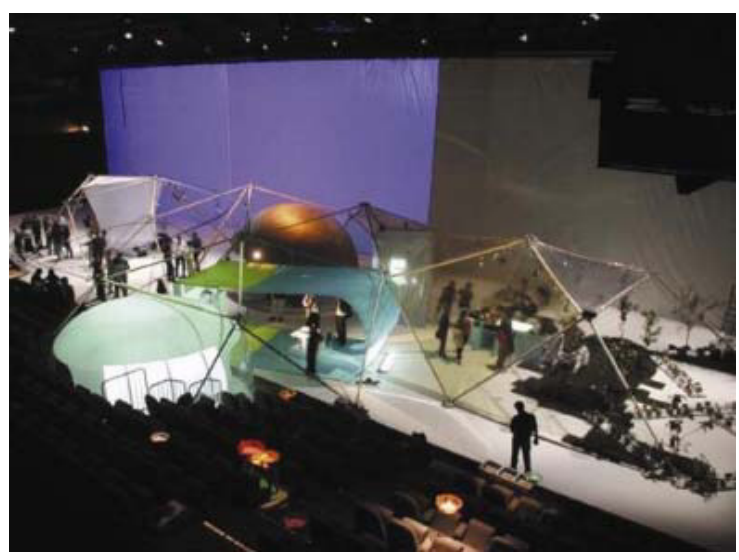

Figure 1: The Media House

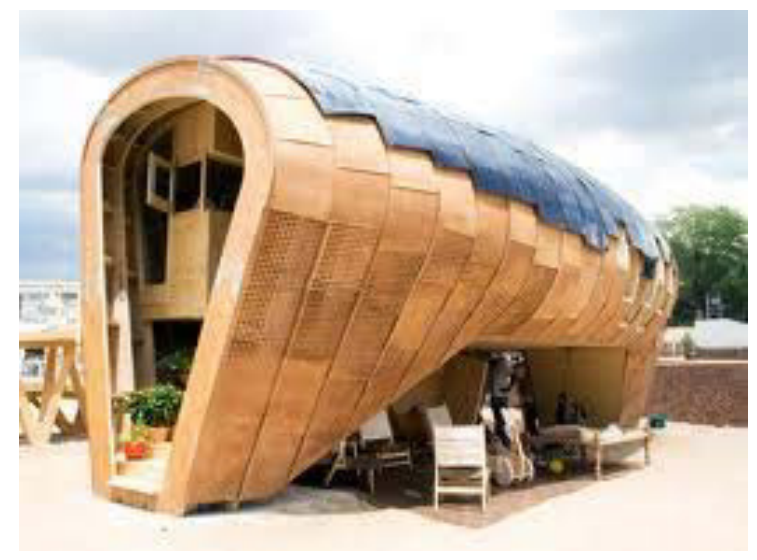

Figure 2: Fab Lab Solar House

This work presents considerations on Ergonomics and Design for Sustainability in the healthcare field based on research experiences of the Technology and Design for Healthcare (TeDH) research group of INDACO (Industrial design, communication, arts and fashion) department of Politecnico di Milano.

\section{Sample research project}

\section{The Babylandia research: design for all and envi- ronmental sustainability in product develop- ment}

Babylandia is a public cofounded project for the promotion of excellence in industrial districts of Lombardy region (2). The goal of the project is to prototype and evaluate children's products for home and collective spaces with the involvement of both university and local companies. Preliminary analyses have been carried out in parallel concerning ergonomics and environmental issues. 


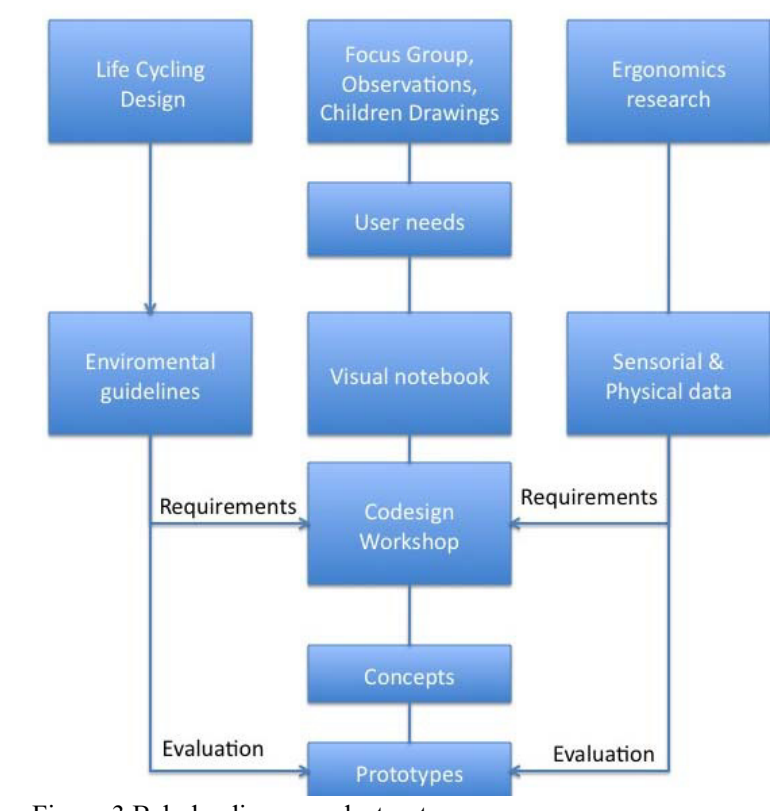

Figure 3 Babylandia research structure.

The research on environmental sustainability has been performed in order to find out critical areas where opportunities for the decrease of environmental impact emerge. Moreover, it has been elaborated a series of strategies, guidelines and environmentally low level impact project indications for the products to be developed following the Life Cycle Design LCD - criteria (8). Furthermore main environmental requirements have been defined for each company's product leading to the organization of a seminar for sustainable idea generation.

In the same time an analysis regarding user needs has been organized on social and individual level. The first one includes three phases: preliminary focus groups with parents and care givers, observations in users' own daily environment during their normal activities and direct children involvement through drawing sessions. The latter, specifically focused on and sensorial requirements and anthropometric parameters of children aged 3-10 years (9), has been integrated through literature reviews.

Consequently a system of toots summarizing the results of those analysis has been developed to support co-design concept development workshops which brought to the development of 4 products: an adjustable seat for disabled children with an ad hoc fabric; a cabinet for children rooms; an interactive floor with LED light; a product for children's protection from electromagnetic radiations and noise.

Prototypes have been produced and finally eva- luated according to ergonomics and environmental requirement previously defined.

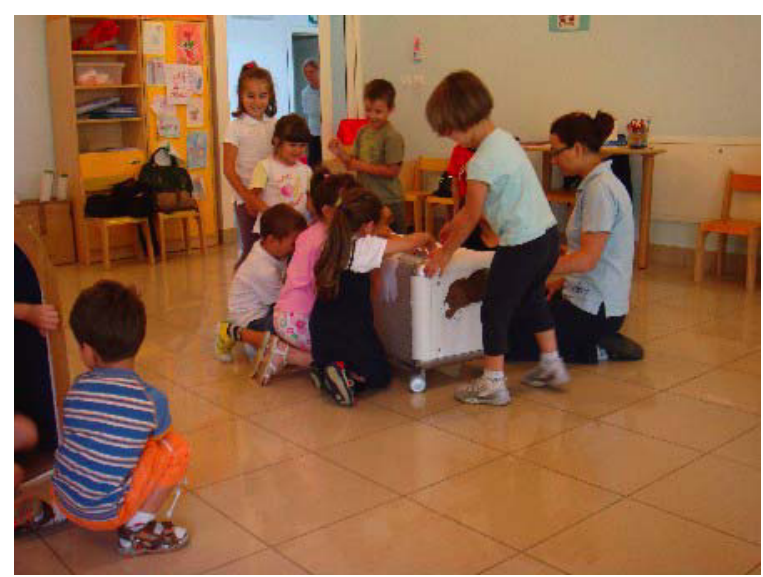

Figure 4: cabinet prototype and user test

User tests conducted in kindergarden showed a high level of usability (10) and pleasure (11) in the interaction with the objects and the application of an environmental quality checklist permitted to assess the application of suggested strategies.

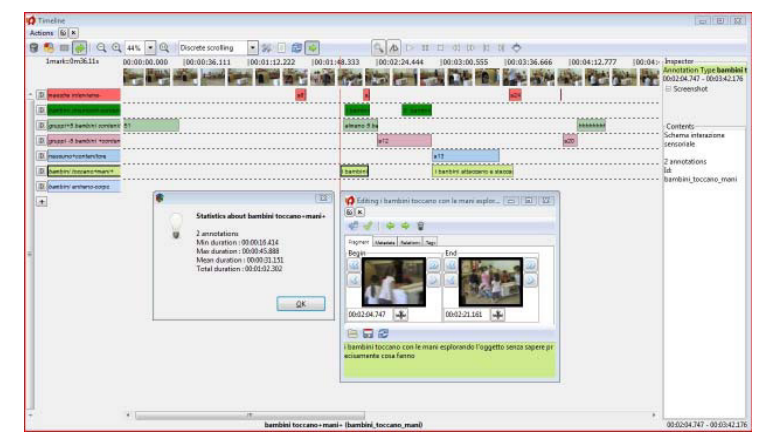

Figure 5: cabinet prototype behavioral evaluation

For example to get a lightweight object and to maximize the use of eco-sustainable materials, the sustainability analysis indicated the use of plastic as appropriate materials for the cabinets doors. The materials choice was successfully also from the user point of view. In fact the tactile interaction induced by the moving parts of the cabinet, such as the wing, proved that the case was easy to use and constructed of attractive materials. The children were very interested in touching, opening and moving the sliding plastic and took advantage of the transparency of the polycarbonate using it as a game. 


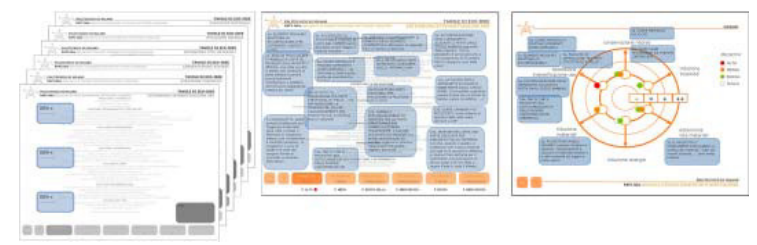

Figure 6: table of eco-generation ideas

\section{The MAMMA research: Ambient Intelligence for ageing.}

MAMMA (Multimodal Ageing Monitoring and Assistance) is also a public funded project involving companies, university and a health care institution aimed at developing a telemonitoring system to support autonomously living elderly people.

MAMMA system is aimed to connect permanently elderly patients with their relatives and care givers. In this way, users can continue to live their everyday life with naturality but continuously monitored as in the hospital. In case of anomalous events or health conditions, the system will provide an alarm to care givers and relatives.

The monitoring is based on two main subsystems that work together in order of define potential dangerous conditions. The first subsystem is composed of wearable sensors that collect biological data (ECG and blood pressure). The second subsystem is based on infrared video-cameras placed in the room in order of collect information related to users movements.

The collected data are transmitted to a hub where they are processed, compared and evaluated. The hub is able to create patterns between biological condition and movements (if the user is sleeping, walking, falling...) and define anomalous situations. Eventual alarms are transmitted to the remote assistant \& health management. The hub provides also access to data and sanitary services through an ad hoc console with different interaction levels according to the different users: elderly people, relatives, caregivers...

In our hypothesis, if it is possible to provide this technology to elderly people and if they accept it, then it will be easy to use it for environmental and social improvement goals. In the situation where technological issues are solved, acceptability is the key factor.

For this reason, an important part of the research is dedicated to usability and acceptability evaluation of the interface console and products.

Design strategy to improve acceptability of ICT and overcome elderly wariness is based on embed- ding cameras (like wardrobes or lamps) and sensors (like patches or undershirts). Early acceptability evaluation is conducted in real environment through Wizard of Oz techniques (12): mock-up of the alternative products have been produced and provided to elderly people involved in the project who were asked to put the pieces of furniture in their home and to dress the wearable devices for one week. Elderly's acceptance and preferences are assessed through focus groups, interviews and diaries filled out by care givers. The physical configuration of the monitoring products and devices is consequently designed according to this results. Final usability evaluation of the whole system is also handled through on site tests.

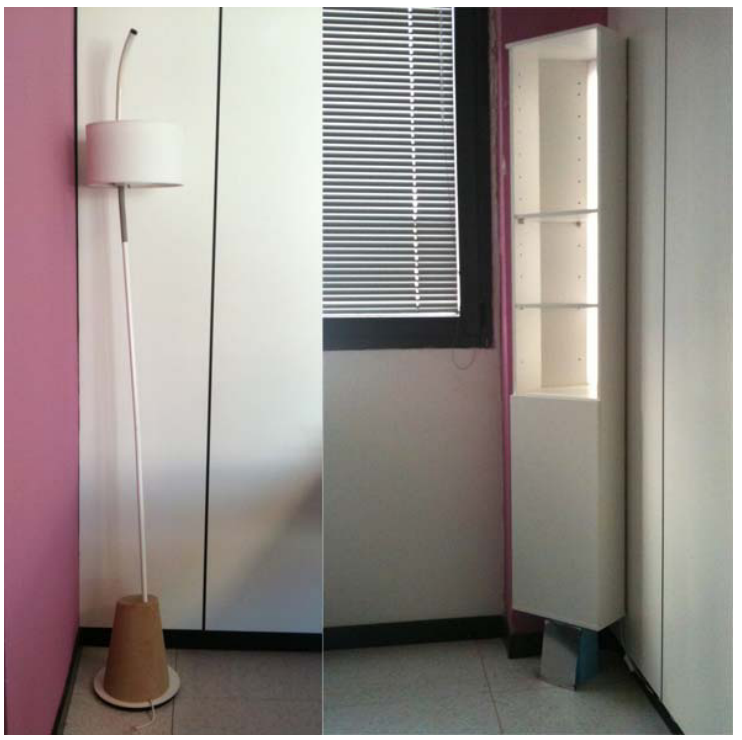

Figure 7: Two prototypes of Lamp with embedded infrared videocamera for home monitoring.

The technical part is devoted to the definition of the systems' architecture and user interface, to the hardware and software development of cameras, accelerometers, biosensors and hub and to the production of prototypes for the final experimentation with end users.

The parallel development of acceptability and technical issues permits to tune the telemonitoring system on elderly psychological and social needs according to User Centered Design principles. As Norman (13) states we are now in a mature phase of technology where product development has to shift from a technology centered to a user centered perspective. 
Creating a network of products, services and people through the support of mobile technologies should also allow a more sustainable assisted ambient living.

\section{Conclusion}

The two samples show the achievement of ergonomics and environmental issues in the first experience presented and the exploitation of ICT to satisfy user needs in the second.

The integrated application of Ambient Intelligence to minimize the environmental impact of home activities and to maximize life quality of inhabitant with special needs like elderly or children is a promising strategy requiring the collaboration of different stakeholders from research and practice community, such as experts in energy consumption, ethnography, physical and cognitive ergonomics, independent designers and architects, staff and managers from manufacturing companies and elderly/disabled care institutions.

Further researches will be needed also to face practical problem as the integration of ICT in existing homes, to experiment the integration of communication technologies into the physical spaces of the domestic environment by means of new interfaces using advanced data networks, integrating information into everyday life.

\section{References}

[1] Melnik, D., et.al (2005), Environment and Human Well-being. A Practical Strategy, United Nations, Earthscan

[2] Andreoni G., Gobo G., Arslan P., Costa C., Muschiato M. Orbetegli L., Romero R., (2010), Sustainable Children's Product Experience, Lens conference, Bangalore

[3] Cordis, Better Technology for Europe's silver surfers, Research UE results magazine, p.31. N³2, March 2011, Luxemburg

[4] Marsili M., Sorvillo M.P. (2002), Previsioni della popolazione residente per sesso, età e regione dal 1.1.2001 al 1.1.2051, Istituto Nazionale di Statistica, ISTAT, Roma 2002

[5] CEIS, Rapporto Sanità 2009, Sanità e sviluppo economico, Fondazione Economia Tor Vergata, Health Communication srl, Roma

[6] http://cordis.europa.eu/fp7/ict/programme/challenge5_en.html

[7] Martin J.L., et.al, (2008), Medical device development: The challenge for ergonomics, Applied Ergonomics 39, pp. 271283

[8] Giudice, F., La Rosa, G., Risitano, A. (2006) Product Design for the Environment. A Life Cycle Approach, CRC Press, Taylor and Francis Group, USA.

[9] Childdata (1998) The Handbook of Child Anthropometric and Strength Measurement, DTI

[10]Rubin, J. (1984) Handbook of usability testing: how to plan, design and conduct effective tests, John Wiley \& sons, New York.

[11] Jordan, P.W. (2000) Pleasure with Products: Beyond Usability, Taylor and Francis

[12] Maudsley, D., Greenberg, S. \& Mander, R., (1993), Prototyping an intelligent agent through Wizard of Oz. in INTERCHI '93 Conference Proceedings, pp. 277-284.

[13] Norman, D. (1998), The invisible computer, MIT Press. 